\title{
A ciência monstruosa em Frankenstein: aspectos do pós-humano
}

Anderson Soares Gomes ${ }^{a}$

\section{Resumo}

Este trabalho tem por objetivo investigar de que maneira as descobertas e o pensamento científico do final do século XVIII e início do século XIX (periodo conhecido como Segunda Revolução Científica) influenciaram a escrita do romance Frankenstein (1818), de Mary Shelley, assim como analisar como essa obra apresenta aspectos que contribuem para o estudo do pós-humano. Frankenstein foi escrito em meio a um contexto de profundas revoluções no pensamento filosófico-científico que informaram diversos elementos presentes no romance: as teorias sociais de William Godwine Mary Wollstonecraft, as hipóteses sobre o princípio da vida de Erasmus Darwin, os experimentos com eletricidade de Luigi Galvani, entre outros. Por outro lado, em uma perspectiva contemporânea, Frankenstein é uma obra que inaugura vários aspectos que viriam a ser lidos pelo prisma do póshumano. Ao descrever as possíveis (e terríveis) consequências da junção da esfera do humano com as do animal e do tecnológico, o romance problematiza a posição privilegiada do homem na natureza. Considerando as características físicas e biológicas do monstro, o desejo de Frankenstein em ultrapassar os limites da natureza, e a complexa relação de ambos os personagens no que se refere ao binômio desejo/ liberdade, o romance pode ser lido como um dos grandes representantes do conceito de pós-humanidade na literatura.

Palavras-chave: Frankenstein, ciência, pós-humano.

Recebido em: 28/08/2018 Aceito em: 25/11/2018

aProfessor do Departamento de Letras da Universidade Federal Rural do Rio de Janeiro (UFRRJ). E-mail: anderson.gomes@gmail.com 


\section{A ciência monstruosa em Frankenstein: aspectos do pós-humano}

Em 2018, celebra-se o aniversário de 200 anos de publicação de Frankenstein, lançado quando sua autora, Mary Shelley, tinha apenas 20 anos. Esse romance, que alcançou dimensões arquetípicas em razão, principalmente, do rico simbolismo produto de sua época e também muito relacionado com questionamentos e tensões da sociedade contemporânea, pode ser lido como um dos primeiros textos literários a representar aspectos do que ficou conhecido como pós-humanidade.

O próprio processo de criação de Frankenstein já adquiriu proporções míticas: a autora, em visita a uma propriedade na Suíça e acompanhada, entre outros, pelos poetas românticos Percy Shelley (que viria a se tornar seu marido) e Lord Byron, entra em uma competição de histórias de fantasmas. Após dois dias, Mary Shelley tem um pesadelo que modificaria não só sua vida, mas toda a literatura ocidental. Na introdução da terceira edição do romance, publicada em 1831, a autora descreve esse sonho terrível:

Eu vi (eu tinha os olhos fechados, mas a visão mental era aguda) o pálido estudante de artes profanas ajoelhado diante da coisa que havia construído. Vi a silhueta horrorosa de um homem deitado que, então, pelo trabalho de alguma máquina poderosa, demonstrou sinais de vida e agitou-se em nervosos movimentos, apenas parcialmente vivos. A cena há de ser aterrorizante - pois supremamente aterrorizante deve ser o que deriva de qualquer tentativa humana de troçar da extraordinária máquina do Criador do mundo (...) Na manhã seguinte, anunciei que já havia pensado em uma história. (SHELLEY, 2017, p. 241-242)

1 Entre eles, Adam Roberts em Science fiction (2000), Lisa Yaszek e Jason W. Ellis em The Cambridge companion to literature and the posthuman (2016) e Cory Doctorow em Frankenstein annotated for scientists, engineers and creators of all kinds (2017).

O ser criado por Victor Frankenstein - ao qual a autora se refere naquele mesmo introdutório como "minha hedionda criatura" - marca, de acordo com vários críticos ${ }^{1}$, o nascimento de um dos gêneros literários contemporâneos por excelência: a ficção científica. Afinal, expõe-se, primeira vez na literatura ocidental, a criação da vida como resultado do pensamento científico e práticas experimentais, em vez de mera consequência de atos mágicos ou sobrenaturais. Porém, é possível afirmar que Frankenstein, além de primeiro romance de ficção científica, também se configura como obra que funda 
ou pelo menos antecipa o conceito de pós-humanidade - como viria a ser conhecido o conjunto de teorias e argumentações sobre modificações em relação à natureza da humanidade no mundo contemporâneo.

Contudo, antes de investigar as maneiras pelas quais Frankenstein prenuncia temáticas da pós-humanidade, fazse necessário compreender o contexto histórico, filosófico e científico que tornou possível a escrita do romance. Mary Shelley arquiteta uma narrativa em que tensões, inovações e teorias, pertencentes a diferentes campos do conhecimento no final do século XVIII e início do século XIX, estabelecem um profundo e profícuo diálogo. E é justamente a riqueza desse diálogo transdisciplinar que servirá de base para diversas teorias relacionadas com o pós-humano na contemporaneidade.

A própria filiação de Mary Shelley já deixa vislumbrar a extensão do contexto sociocultural ao qual a autora inevitavelmente pertencia. Filha do filósofo radical do final do século XVIII William Godwin e da escritora "protofeminista" Mary Wollstonecraft, o pensamento de Shelley foi em grande parte moldado pelos escritos de seus pais. Porém, a influência desses dois grandes pensadores muitas vezes serviu como ponto de partida para que a autora explorasse seus próprios questionamentos. Como afirma a pesquisadora Pamela Clemit:

Escrevendo com uma percepção de como as políticas da Revolução Francesa se desdobraram durante o Período Napoleônico, Mary Shelley amplia e reformula os múltiplos legados de Godwin e Wollstonecraft de forma extrema e imaginativamente impactante. (CLEMIT, 2003, p. 26, tradução nossa) $)^{2}$.

Com a morte de Wollstonecraft poucos dias após o parto de Mary Shelley (ainda Mary Godwin), coube a William Godwin a educação da filha. Desde cedo, era do entendimento do filósofo que a jovem Mary, assim como seus outros filhos,

2 "Writing with an awareness of how French revolutionary politics had unfolded th ro u h $\mathrm{th}$ e Napoleonic era, Mary Shelley extends and reformulates the manysided legacies of Godwin and Wollstonecraft in extreme, imaginatively arresting ways." deveria ter acesso ao conhecimento artístico e científico do início do século XIX. Sendo assim, não apenas Mary Shelley pôde conhecer pessoalmente os grandes nomes da primeira geração romântica inglesa, como William Wordsworth e Samuel Taylor Coleridge, como também teve acesso a palestras e obras de homens que estavam revolucionando a ciência do período, como Humphry Davy e Luigi Galvani. 
Por outro lado, o papel de William Godwin na educação de Mary Shelley deu-se de forma marcante também por meio de suas obras e ideias, consideradas radicais para a época. De maneira geral, o pensamento de Godwin, expresso em obras como Enquiry concerning political justice (1793) e Things as they are; or The adventures of Caleb Williams (1794), tem como base discutir a corrupção moral instituída pela aristocracia, de forma que "os indivíduos, por meio do exercício da razão e julgamento próprio, têm o poder de se emancipar [...], levando à gradual dissolução de todas as limitações legislativas." (CLEMIT, 2003, p. 28, trad. livre). As origens aristocráticas de Victor Frankenstein, assim como a gradual consciência de classes que a criatura adquire no decorrer do romance, deixam entrever a influência dos escritos de Godwin em Frankenstein. Além disso, Mary Shelley, deixando clara sua filiação familiar, mas também filosófica com relação a Godwin, dedicou a primeira edição da obra ao autor ${ }^{3}$.

Mesmo não tendo conhecido sua mãe, vítima de complicações pós-parto catorze dias após o seu nascimento, Mary Shelley foi leitora ávida dos escritos de Mary Wollstonecraft, considerada uma das primeiras autoras a reivindicar direitos e criticar injustiças sociais no que concerne às mulheres. Um dos aspectos centrais da obra de Wollstonecraft - o poder formativo da educação e sua importância na construção da moralidade - informa muito da relação entre Victor Frankenstein e o monstro. A criatura, abandonada por seu criador, é privada de um aprendizado formal sobre a sociedade e as relações humanas, o que acaba contribuindo para a formação de um comportamento moral guiado pela vingança e pelo crime. Em termos de organização narrativa, Frankenstein também possui bastante em comum com Maria: or The wrongs of woman (1792) de Wollstonecraft. A multiplicidade de vozes narrativas, às vezes contando o mesmo episódio de diferentes pontos de vista, com ênfase na relação entre moralidade e responsabilidades sociais, é uma estratégia presente em ambos os romances.

Não foram apenas as obras de seus pais, contudo, que

O texto da dedicatória no original é: "To William Godwin, author of Political Justice, Caleb Williams, \&c. These volumes are respectfully inscribed by the author." tiveram influência na produção literária de Mary Shelley. Escrito em um período de profundas mudanças sociais, políticas e científicas na Europa, Frankenstein acabou por servir de receptáculo para as novas ideias e eventos que construíram esse contexto revolucionário. Como afirma a crítica literária 
Lisa Vargo, "assim como a criatura, que é produto da junção de materiais, o romance em si é um palimpsesto das próprias leituras de Mary Shelley." (VARGO, 2016, p.26, trad. livre).

As teorias filosóficas de John Locke e Jean-Jacques Rousseau, os escritos históricos de Volney, os versos de John Milton, Samuel Taylor Coleridge e William Wordsworth - todo esse rico amálgama de conhecimento serviu como base para a construção narrativa de Frankenstein, muitas vezes sendo mencionados e lidos por Frankenstein ou pela criatura no decorrer do romance. No entanto, provavelmente o maior impacto no processo de escrita do romance se deve ao processo de descobertas e avanços científicos ocorridos no final do século XVIII e início do XIX. Foi um período de intensas mudanças no entendimento do homem e da natureza, além de uma notória aproximação entre o conhecimento científico e experimentos que beiravam o fantástico. É nesse território entre a ciência e o deslumbramento que Frankenstein vai surgir.

Conhecido como Segunda Revolução Científica ${ }^{4}$, esse período foi marcado pela aproximação do conhecimento científico com o movimento artístico-literário em ascensão na época: o Romantismo. Tendo forte impacto especialmente na Inglaterra, essa nova visão sobre a ciência foi marcada por escritos de autores românticos sobre descobertas nos campos da química e da filosofia natural, assim como por uma sensibilidade artístico-criativa nos preceitos que informam muitos dos cientistas da época. O historiador Richard Holmes, em seu livro The age of wonder, descreve a Segunda Revolução Científica da seguinte forma:

4 O período conhecido como Primeir a Revolução Científica é normalmente associado a mudanças no pensamento científico e filosófico do século XVII, proporcionadas por figuras como Newton e Descartes. O termo "Segunda Revolução Científica", para se referir ao conjunto de descobertas científicas do início do século XIX, foi provavelmente usado pela primeira vez por Samuel Taylor Coleridge em Philosophical Lectures (1819).
Foi um movimento que surgiu do racionalismo iluminista do século dezoito, mas que em grande parte o transformou, ao trazer uma nova intensidade imaginativa e entusiasmo para o trabalho científico. Ele foi guiado por um intenso, até mesmo irresponsável, ideal comum de compromisso pessoal com descobertas. (HOLMES, p.xvi, 2009, tradução nossa).

De forma perspicaz, Holmes também comenta que esta ligação entre o Romantismo e a ciência gera uma tensão: as descobertas e invenções dessa "ciência romântica" trariam esperança ou terror para o mundo? (HOLMES, p.xix, 2009.) De certa forma, esse é um dos grandes questionamentos de toda a ficção científica como gênero literário, e certamente uma das principais temáticas de Frankenstein. 
O prefácio escrito por Percy Shelley para a primeira edição do romance, publicada em 1818, inicia-se justamente apresentando como os acontecimentos descritos na narrativa são fruto das inovações científicas da época associadas ao poder imaginativo - e essencialmente romântico - da autora:

O acontecimento que fundamenta esta ficção já não é considerado, segundo o dr. Darwin e alguns dos fisiologistas alemães, impossível. Não se deve presumir que eu atribua o mais remoto grau de fé e seriedade a tais devaneios; não obstante, ao aceitar que funcionam como argumento para um trabalho de fantasia, não julgo que apenas teço fios de horrores sobrenaturais. $\mathrm{O}$ acontecimento de que depende o interesse da história está isento das desvantagens de um conto qualquer de fantasmas e magia. Encontra lastro na novidade das situações que desenvolve; e, embora impossível como fato físico, oferece um ponto de vista a partir do qual a imaginação delineia as paixões humanas de maneira mais ampla e segura do que caberia nos limites de um elenco comum de fatos existentes (SHELLEY, 2017, p. 235).

Nota-se que o prefácio estabelece que o experimento científico descrito na obra, considerando as recentes descobertas do período, não pode ser considerado inconcebível. Para sustentar essa afirmação, Erasmus Darwin é citado como figura-chave. $\mathrm{O}$ mais famoso divulgador científico de seu tempo, Darwin foi um cientista - mas também poeta -, amigo de William Godwin, e que Mary Shelley provavelmente deve ter conhecido. Percy Shelley era leitor das obras poéticas e científicas de Darwin, e os experimentos e teorias do avô de Charles Darwin foram assunto durante o mítico verão em que a ideia de Frankenstein foi concebida, como afirma Mary Shelley no prefácio escrito por ela para a edição de 1831:

Muitas e longas foram as conversas entre Lord Byron e Shelley, das quais eu era ouvinte dedicada, porém quase muda. Durante uma delas, várias doutrinas filosóficas foram discutidas - entre elas, a da natureza do princípio da vida, e se havia alguma possibilidade de esta ser descoberta e transmitida. Conversaram sobre os experimentos do Dr. Darwin [...], que conservou um pedaço de aletria num vidro até que, de maneira extraordinária, este começou a se mover por vontade própria. (SHELLEY, 2017, p. 240).

O questionamento sobre a "natureza do princípio da vida" é uma das temáticas centrais de Frankenstein, e muito do entendimento de Victor Frankenstein sobre a forma de 
concepção da criatura deve-se às teorias científicas de Darwin. Primeiramente, Frankenstein entende que os princípios responsáveis por criar vida não podem ser compreendidos meramente com o estudo da anatomia. De acordo com o personagem, "para examinar as causas da vida, precisamos primeiro entender a morte [...] devia também observar a decadência natural e a corrupção do corpo humano." (SHELLEY, 2017, p.59) É durante suas visitas a cemitérios para investigar os entre-lugares entre a vida e a morte que Frankenstein é inundado pela "luz brilhante e maravilhosa" (SHELLEY, 2017, p. 60) de como criar a vida por meio da ciência.

Em seus textos, Darwin deixava claro sua certeza de que os elementos responsáveis pela criação da vida estavam invariavelmente ligados à morte dos seres vivos. Em seu artigo "Spontaneous Vitality of Microscopic Animals", o cientista afirma que "os mais simples animais e vegetais podem ser produzidos pela junção das partes de matéria orgânica em decomposição" (DARWIN apud SMITH, 2016, p.75, tradução nossa). Essa conexão entre vida e morte é explorada pelo autor em outra obra, Phytologia; or, The Philosophy of Agriculture and Gardening (1800), quando ele afirma que restos mortais podem enriquecer o solo e favorecer o crescimento de vegetação (DARWIN apud SMITH, 2016, p.75, tradução nossa). Mesmo em sua produção poética, como The Temple of Nature (1803), Darwin afirma que a vida é gerada por meio da morte.

Outro fator que alinha as atitudes de Victor Frankenstein ao pensamento de Erasmus Darwin diz respeito às características da concepção de uma nova criatura por meio do método científico. Frankenstein ambiciona formar uma nova criatura e, a partir daí, receber os louros e o agradecimento por ter sido capaz de realizar tal ato - ele seria o "pai orgulhoso", que poderia regozijar-se por ter concebido um novo ser. Além disso, é uma concepção essencialmente masculina, que prescinde da presença feminina para a realização desse parto não normal como afirma a crítica Anne K. Mellor, Frankenstein é "um livro sobre o que acontece quando um homem tenta procriar sem uma mulher." (MELLOR, 2003, p.10, tradução nossa). Esses aspectos do romance parecem ser fortemente influenciados também pelo poema The Temple of Nature de Darwin, quando o autor aborda os conceitos de reprodução e criação da vida: 
In these lone births no tender mothers blend Their genial powers to nourish or defend;

No nutrient streams from Beauty's orbs improve

These orphan babes of solitary love;

Birth after birth the line unchanging runs,

And fathers live transmitted in their sons;

Each passing year beholds the unvarying kinds,

The same their manners, and the same their minds.

(DARWIN in: WOLFSON \& LEVAO, 2012, p.61) ${ }^{5}$

5 "Nesses isolados nascimentos nenhuma mãe terna mistura

Seus poderes amáveis para alimentar ou defender;

Nenhum fluxo de nutrientes das órbitas da Beleza beneficia

Esses bebês órfãos do amor solitário;

Nascimento após nascimento a linha segue imutável,

E pais permanecem vivos em seus filhos;

Cada ano que passa testemunha os tipos invariáveis,

Com os mesmos comportamentos e pensamentos"

6 "Corre o rápido Éter pelos caminhos de fibras

De artérias dançantes e ardentes veias

Estimulando cada excelente nervo com novas excitantes sensações

$\mathrm{Sub}$ m e tendo os membros relutantes a um poder involuntário."
Já no primeiro verso dessa passagem, o poeta-cientista ressalta a ausência das mães, enfatizando como o processo de criação se restringe a uma relação entre pai e filho. Além disso, fica claro como o filho serve como receptáculo para as características do pai, sendo causa de orgulho para o progenitor. As semelhanças de comportamento entre criador e criatura em Frankenstein - a ponto de, no senso comum, serem identificados pelo mesmo nome - parecem confirmar o ponto de vista darwinista.

Darwin também apresentava grande interesse sobre o estudo da eletricidade, especialmente no efeito que a corrente elétrica poderia ter no controle de corpos e mentes. Em seu poema The Botanic Garden, o autor escreve:

Starts the quick Ether throught the fibre-trains

Of dancing arteries, and of tingling veins,

Goads each fine nerve, with new sensations thrill'd,

Bends the reluctant limbs with power unwill'd.

DARWIN in: SMITH, 2017, p.75) ${ }^{6}$

A eletricidade talvez seja o campo da ciência desenvolvido durante a Segunda Revolução Científica que mais tenha influenciado a escrita de Frankenstein. Durante o século XIX, diversos experimentos e apresentações que procuravam estabelecer uma relação entre a corrente elétrica e os mistérios da origem da vida se tornaram extremamente populares, ocupando o imaginário de grande parte da população inglesa e certamente compondo o arcabouço de referências científicas que informaram a escrita de Mary Shelley.

No prefácio da edição de 1831 de Frankenstein, a autora deixa antever que estava ciente das discussões que tinham como assunto a aproximação entre eletricidade e origem da vida: "Talvez um cadáver pudesse ser reanimado; o galvanismo havia oferecido pistas nesse sentido: talvez os componentes de 
uma criatura pudessem ser fabricados, montados e dotados de calor vital." (SHELLEY, 2017, p.240). Mesmo que não exista no romance menção específica da eletricidade tendo papel na criação do monstro, é extremamente provável que os avanços nesse campo da ciência ao final do século XVIII e início do XIX em muito informaram o pano de fundo científico da escrita de Frankenstein.

O termo "galvanismo", usado por Shelley no prefácio de 1831, foi como ficou conhecido o tipo de experimento em que a condução de uma corrente elétrica é capaz de causar a contração de músculos. O nome dessa área da biologia é originário dos estudos do professor de anatomia Luigi Galvani (1737-1798). Ao final do século XVIII, Galvani realizou seu famoso experimento em que pernas de rãs se contraíram ao entrar em contato com descargas elétricas. A partir daí, a noção de um fluído vital que animava a todos os seres vivos passou a ser relacionado diretamente com a eletricidade.

O galvanismo tornou-se mais conhecido ao servir de base para eventos espetaculosos em que animais e até mesmo cadáveres eram usados para comprovar as descobertas de Galvani. As mais famosas dessas apresentações eram conduzidas por Luigi Aldini, também professor e sobrinho de Galvani. Em uma célebre performance ocorrida em Londres em 1802, Aldini tentou reanimar o corpo de um criminoso que havia sido enforcado recentemente. O episódio foi altamente divulgado pelos jornais da época:

$\mathrm{Na}$ primeira aplicação do processo à face, a mandíbula do criminoso morto começou a se contrair, os músculos adjacentes ficaram horrivelmente contorcidos, e um olho de fato se abriu. Na parte seguinte do processo, a mão direita se levantou e fechou, e as pernas e coxas foram postas em movimento. Pareceu à parte desinformada dos espectadores como se o pobre homem estivesse prestes a ser restituído à vida. (HITCHCOCK, 2010, p. 38-39)

É bastante provável que Mary Shelley tenha tomado conhecimento desses experimentos que capturaram o imaginário da Inglaterra no início do século XIX. Evidência disso é que seu romance faz constantes referências ao poder criador - mas também arrasador - da eletricidade. Um dos primeiros momentos em que Victor Frankenstein presencia a 
imensa força da natureza é quando ele, ainda na adolescência, testemunha uma intensa tempestade:

Os trovões irrompiam com um temoroso estrondo de vários cantos do céu. Permaneci, durante o temporal, observando seu progresso com curiosidade e encanto. De péá porta, vi de repente uma língua de fogo sair de um velho e belo carvalho [...] Quando fomos vê-lo na manhã seguinte, encontramos a árvore despedaçada de uma maneira singular [...] Nunca contemplara nada tão completamente destruído. Na época, eu não desconhecia as leis mais óbvias da eletricidade. Naquela ocasião, um homem de grande pesquisa em filosofia natural estava conosco e, empolgado pela catástrofe, entrou na explicação de uma teoria que havia formulado sobre eletricidade e galvanismo, que era ao mesmo tempo nova e espantosa para mim. (SHELLEY, 2017, p.49)

Frankenstein, portanto, tinha conhecimento dos experimentos galvânicos e, ao testemunhar o ímpeto da eletricidade, passa a considerar essa nova forma de conhecimento que ultrapassa o entendimento da natureza de uma perspectiva alquímica como ilustrada por Agrippa ou Paracelso. Além disso, é interessante notar como a palavra spark (faísca, centelha), normalmente relacionada com a eletricidade, é geralmente, no romance, associada ao processo de criação da vida - em especial no momento de criação do monstro, em que Frankenstein fala em "infundir uma centelha [spark] na coisa inanimada aos meus pés." (SHELLEY, 2017, p.65).

Os experimentos de Darwin e Galvani foram essenciais para formar o arcabouço científico de Frankenstein, mas não foram os únicos. Por ser uma ávida leitora e estar inserida no revolucionário contexto do início do século XIX, a autora provavelmente teve acesso a diversas outras concepções da ciência: a nova terminologia química de Humphry Davy e sua ideia de que o cientista deve assumir uma posição ativa com relação à natureza; os debates entre John Abernathy e William Lawrence com relação a uma esotérica "força vital" que estaria presente em todos os seres humanos; as experimentações proibidas de Johann Wilhelm Ritter envolvendo tentativas de reanimação de cadáveres - todo esse inovador conjunto de maneiras de pensar o homem e a natureza engendrou a Segunda Revolução Científica e serviu de alguma maneira para a criação de Frankenstein. Afinal de contas, o romance marca uma "transição em narrativas de seres humanos criando vida, já que 
Victor Frankenstein não invoca a ajuda de alguma divindade ou qualquer outra agência sobrenatural." (HOUE, 2016, p.102) - é a partir do conhecimento científico que a vida é gerada.

Se Frankenstein tematiza narrativamente a estrutura filosófico-científica do final do século XVIII e início do XIX, o romance também antecipa questões dessa ordem a partir de meados do século XX - em especial nos campos da biologia, da genética e da cibernética. É a partir desse período que avanços no campo tecnocientífico passam a tornar possível experimentos apenas idealizados na época de Darwin e Galvani. Por outro lado, esse desenvolvimento de novas formas de conhecimento ressignifica a potência de Frankenstein como obra-chave para entender também a contemporaneidade.

Nessa perspectiva, o romance de Mary Shelley pode ser lido como provavelmente a primeira obra literária a abordar de maneira bem-sucedida o que viria a ser conhecido como "pós-humano". Ainda hoje, não há uma definição de póshumanidade que seja consenso entre críticos e estudiosos do tema. O termo "pós-humanidade" em si já se constitui como motivo de discussão, já que alguns preferem "póshumanismo", com o intuito de contrastar com um arcabouço filosófico humanista.

Em linhas gerais, o termo "pós-humanidade" pode ser entendido pelo menos de duas maneiras, partindo do entendimento do prefixo "pós": primeiramente, seria aquilo que viria após o homem, ou seja, depois do desaparecimento da humanidade, o pós-humano seria aquilo que serviria como substituição ao humano sendo consequência do desaparecimento deste; de outro modo, o pós-humano seria aquilo que ultrapassa o humano, com características superiores e sendo causa do desaparecimento deste.

Mesmo que alguns autores argumentem que é possível encontrar traços do que hoje chamamos de pós-humano em textos da Idade Média e do início da Idade Moderna (especialmente tendo em vista a aproximação entre póshumanidade e ecocrítica), é no século XX que o conceito passa a configurar como discurso fundamental da crítica contemporânea. As chamadas “Conferências Macy”, ocorridas em Nova York entre as décadas de 1940 e 1960, por exemplo, são consideradas um marco da pós-humanidade, pois nessa série de encontros entre pesquisadores de diferentes áreas, pela 
7 Chama a atenção a presença da referência à divindade da mitologia grega Prometeu nesse que é um dos textos fundadores do conceito de pós-humanidade. O mito de Prometeu também é metaforizado de forma explícita por Mary Shelley em Frankenstein - prova disso é que o subtítulo do romance é "O Moderno Prometeu".

8 "Posthumanist discourses promote $\mathrm{n}$ e i $\mathrm{th}$ e $\mathrm{r} \quad \mathrm{t} \mathrm{h}$ e transcendence of the human nor the negation of humanism. Rather, critical posthumanisms engage with the humanist legacy to critique anthropocentric values and worldviews. Posthumanist scholars have brought attention to the potential as well as the fault lines of humanist knowledge production while also problematizing the narrative of the progressive trajectory of the posthuman." primeira vez foram discutidas temáticas como cibernética e estímulos neurofarmacológicos. Mesmo sem utilizar o termo "pós-humanidade", ideias sobre o futuro do homem já se faziam presentes na filosofia e estudos culturais, sendo um bom exemplo esta passagem do capítulo final de As Palavras e as Coisas, de Foucault:

Durante todo o século XIX, o fim da filosofia e a promessa de uma cultura próxima constituíam, sem dúvida, uma única e mesma coisa, juntamente com o pensamento da finitude e o aparecimento do homem no saber; hoje, o fato de que a filosofia esteja sempre e ainda em via de acabar e o fato de que nela talvez, porém mais ainda fora dela e contra ela, na literatura como na reflexão formal, a questão da linguagem se coloque, provam sem dúvida que o homem está em via de desaparecer. (FOUCAULT, 1999, p.412)

Contudo, o conceito de uma "cultura pós-humana" provavelmente só emerge no meio das chamadas Ciências Humanas (ou seriam Pós-Humanas?) em 1977, com o artigo de Ihab Hassan "Prometheus as Performer: Toward a Posthumanist Culture? A University Masque in Five Scenes", que, na verdade, compunha um roteiro para apresentações artísticas ${ }^{7}$. Nesse texto, Hassan diz que "precisamos entender que quinhentos anos de humanismo podem estar chegando ao fim, à medida que o humanismo se transforma em algo que devemos chamar inevitavelmente de pós-humanismo" (HASSAN, 1977, p. 843).

Com o crescimento de pesquisas sobre pós-humanidade em terrenos tão diversos da contemporaneidade quanto estudos literários, ciências biológicas, cibernética e ecocrítica, a acepção do termo foi evoluindo e adaptando-se a realidades sociobiotecnológicas cada vez mais complexas e avançadas. $\mathrm{O}$ Cambridge Companion to Literature and the Posthuman apresenta a seguinte definição:

Discursos pós-humanistas não propõem a transcendência do humano nem a negação do humanismo. Em vez disso, pós-humanismos críticos se relacionam com o legado humanista para criticar valores e visões de mundo antropocêntricos. Estudiosos do pós-humanismo chamam a atenção para o potencial e também para os enganos da produção de conhecimento humanista ao mesmo tempo em que problematizam a trajetória progressiva do pós-humano. (CLARKE \& ROSSINI, 2017, p. xiv, tradução nossa) ${ }^{8}$. 
Dessa forma, estudos sobre pós-humanidade não têm a ambição de rejeitar todos os "quinhentos anos de humanismo" como afirmou Hassan, nem se enveredar profundamente pelos estudos da transcendência (experiências extracorpóreas possibilitadas por artefatos tecnológicos, como implantes de memória, por exemplo). Um dos aspectos mais marcantes dos estudos pós-humanos é investigar as maneiras pelas quais os discursos do corpo, da ciência e do progresso são (des) construídos no mundo contemporâneo.

De maneira geral, o pós-humano é representado por uma imagem, real ou especulativa, que une o humano a alguma espécie ou elemento não humano (CLARKE \& ROSSINI, 2017, p. xiii). Desde o início do século XX, são diversas as produções artísticas e culturais que vêm tematizando noções do pós-humano. Androides e ciborgues, por exemplo, são as figuras-chave desse tipo de obra, associando questões sobre o corpo e o conceito de "natural" a tópicos sobre tecnologia e o conceito de "artificial". Entre essas produções, algumas das mais emblemáticas são o filme Metrópolis (1927), de Fritz Lang; o romance Do Androids Dream of Electric Sheep? (1968), de Philip K. Dick, e sua influente adaptação cinematográfica Blade Runner - O Caçador de Androides (1982), de Ridley Scott; Neuromancer (1984), de William Gibson, romance-chave da literatura cyberpunk; e o filme Robocop - O Policial do Futuro (1987), de Paul Verhoeven. Produções mais recentes como os filmes Ela (2013) de Spike Jonze e Ex-Machina (2014), de Alex Garland, além das séries de TV Westworld e Altered Carbon, também têm relação direta com essa temática. No terreno das artes plásticas, obras de artistas contemporâneos, como Ron Mueck e Patricia Piccinini, rompem as barreiras entre o sublime e o grotesco, criando um estranhamento que emerge justamente por meio dos aspectos pós-humanos de suas criações.

A presença de elementos pós-humanos em Frankenstein se dá de maneira mais evidente por meio da criatura. $\mathrm{O}$ monstro criado por Victor Frankenstein, produto não de uma concepção natural nem de forças sobrenaturais, mas resultado de um experimento científico, ilustra um exemplo do pós-humano ao ser composto pela junção do humano ao não humano. Frankenstein descreve da seguinte forma parte do processo de criação do monstro: 
Quem pode conceber os horrores de minha labuta secreta, enquanto eu chafurdava na terra profana dos túmulos ou torturava animais vivos para animar o barro sem vida?

(...) Coletava ossos de mausoléus e perturbava, com dedos profanos, os segredos grandiosos da constituição humana [...] A sala de dissecação e o matadouro forneciam muitos dos materiais (SHELLEY, 2017, p.62)

O monstro é constituído, portanto, de um amálgama de partes de diferentes cadáveres e também possivelmente de animais, já que Frankenstein revela que muitos dos seus materiais de trabalho eram oriundos de matadouros. Essa fusão de corpos em decomposição e partes de animais costurados por meio do conhecimento científico marca o caráter de monstruosidade pós-humana caracterizada no romance:

O composto humano-animal é apenas uma figuração do póshumano na literatura. Do outro lado está o composto humanotecnologia onde estamos unidos ao tecnológico: humanos como ciborgues. Na criatura de Frankenstein, nós temos os dois. A criatura é animal, humana e tecnológica ao mesmo tempo. (CLARKE; ROSSINI, 2017, p. 37, tradução nossa.)

Dessa forma, a pós-humanidade como conceito está regularmente associada a uma multiplicidade de componentes unidos com o intuito de gerar uma completude, mas cujo fruto é, em geral, monstruoso.

A qualidade monstruosa da formação fragmentada do monstro espelha a monstruosidade presente na formação fragmentada do romance. A própria Mary Shelley parece compartilhar dessa interpretação quando, de maneira perspicaz, escreve no prefácio da edição de 1831: "peço a minha criatura medonha que siga seu caminho e seja feliz" (SHELLEY, 2017, p.242). O duplo sentido proposital - a "criatura medonha" pode se referir ao monstro mas também ao próprio romance - confirma a noção de que a criatura e o romance são um só, partilhando das mesmas características.

Como mencionado anteriormente nesse trabalho, o romance de Mary Shelley apresenta inúmeras influências filosóficas, históricas, científicas e literárias. A agregação desses variados conhecimentos, que vão de Milton a Rousseau, de Godwin a Galvani, pode ser associada ao caráter múltiplo que é associado ao monstro. O crítico literário Chris Baldick chega a afirmar que existe "uma provisão de fontes literárias de que 
Frankenstein se alimenta canibalisticamente." (BALDICK apud HALBERSTAM, 1995, p.33, trad. livre).

Além disso, a estrutura narrativa de Frankenstein, assim como a do monstro, é composta de diferentes partes que, quando costuradas, produzem um resultado assustador:

Frankenstein consiste de três "círculos concêntricos" denarração (as cartas de Walton, a narrativa de Victor Frankenstein a Walton, e o discurso do monstro a Frankenstein), dentro dos quais estão inseridos pedaços de digressão contendo outras narrativas em miniatura (a história da mãe de Frankenstein, as histórias de Elizabeth Lavenza e Justine, a história de Felix e Agatha, a história de Safie etc) (GILBERT \& GUBAR in: SHELLEY, 1996, p.229, trad.livre).

O romance, portanto, ao ser constituído por diversas vozes narrativas, histórias e digressões, pressupõe uma diegese pós-humana, ou seja, uma dimensão ficcional múltipla que abarque diferentes identidades (masculinas, femininas, eurocêntricas, orientais, naturais ou não-naturais) narrando a partir de seus pontos de vista. Dessa forma, a estrutura do romance compõe-se de possibilidades autobiográficas póshumanas, à medida que os narradores, ao mesmo tempo em que contam suas histórias, escutam as histórias de outros, questionando sua própria humanidade enquanto tentam manter sua própria subjetividade (MOUSLEY, 2016, p.169).

Essa formação fragmentada, tanto do romance quanto da criatura, desafia categorizações. No caso da criatura, um dos principais debates da crítica é com relação à sua localização no espectro da pós-humanidade. Chamado de "monstro", "demônio" e "maldito" no decorrer da obra, seria ele membro de uma nova raça de seres humanos? Ou totalmente pertencente a uma nova espécie distinta da espécie humana?

O próprio romance é ambíguo em suas definições. Ao descobrir o segredo da criação da vida, Frankenstein questiona sua habilidade de "dar vida a um animal tão complexo e maravilhoso quanto o homem" (SHELLEY, 2017, p. 61). Algumas linhas depois, ele abandona o tom comparativo e afirma categoricamente que deu "início à criação de um ser humano (SHELLEY, 2017, p.61). Porém, logo a seguir, ele diz que "uma nova espécie iria me abençoar como seu criador e origem (SHELLEY, 2017, p.61). Se o criador tem dúvidas na categorização do resultado de seu experimento, a criatura parece estar mais 
certa de pertencer a uma espécie completamente nova. Ao comparar-se com os De Laceys e considerar-se horrendo e abjeto, a criatura diz que "não era nem da mesma natureza do homem" (SHELLEY, 2017, p.129). Em seguida, ao ser rejeitado, declara "guerra eterna contra a espécie [humana]" (SHELLEY, 2017, p.145), marcando claramente sua posição de alteridade. E ao solicitar a Frankenstein uma companheira, ele diz que "minha companhia deve ser da mesma espécie e ter os mesmos defeitos" (SHELLEY, 2017, p.152).

De certa forma, é essa indefinição sobre a natureza da criatura que marca sua condição pós-humana. E se para o monstro sua posição como biologicamente diferente está clara, para seu criador a dúvida persiste justamente pela ansiedade usual que o pós-humano desencadeia. Se considerada como ser da mesma espécie, a criatura pode pôr em xeque a condição de superioridade da humanidade e evidenciar a monstruosidade que se faz presente também no homem. Se vista como membro de uma espécie distinta, a criatura pode servir como símbolo de uma nova fase, em que seres humanos e seus traços distintos se tornarão supérfluos e ultrapassados, sendo substituídos ou obliterados por uma espécie superior. Em qualquer uma das duas acepções, a sensação de primazia do homem é colocada em questão, tendo a condição pós-humana da criatura como ameaça. Como afirma o crítico Ron Broglio:

A criação de Frankenstein coloca o humano ao lado da cadeia de outros animais sem privilegiar os humanos. Isso significa que as únicas criaturas que privilegiam o humano são os próprios humanos; fora de nosso próprio círculo, não há doutrina transcendental, nenhuma autoridade universal que autoriza esse senso de privilégio. A razão e o pensamento humano são uma ilha deserta em um mar de diferentes sistemas semióticos em um universo indiferente. (BROGLIO, p.37, tradução nossa) ${ }^{9}$.

Vale destacar que, mesmo que entendamos o monstro como representante de uma categoria pós-humana da existência, devemos problematizar a ideia de que ele faz parte de uma nova raça. Uma das marcas da pós-humanidade é justamente a ausência de fixidez geográfica, social ou biológica. O monstro não possui uma nacionalidade, não pertence a nenhuma classe social e, também, a nenhuma "raça" no sentido que conhecemos (apesar de diversos críticos lerem a criatura 
como representante dos anseios anti-irlandeses e antiafricanos da época). Sendo assim, o caráter único e solitário do monstro o impede de ser pertencente a uma ideia de "nova raça". Nesse sentido, o teórico Patrick Brantingler é categórico ao afirmar:

Por definição, uma raça é toda uma população, e geralmente uma população numerosa: todos os mongóis, por exemplo, ou todos os caucasianos. Não faz sentido se referir a todos os monstros (...) como uma categoria de população; eles são tipicamente figuras insociáveis ou singularidades monstruosas, criaturas solitárias além das fronteiras da civilização, que é exatamente a situação em que o monstro de Frankenstein se encontra depois que seu criador o abandona (BRANTINGLER, p..137-138, tradução nossa.) ${ }^{10}$

Se a pós-humanidade da criatura de Frankenstein está devidamente evidenciada por causa de sua composição corporal, formada de diferentes partes humanas e de animais, sua composição identitária também manifesta formas de subjetividade que ultrapassam as noções consolidadas do humanismo - uma identidade pós-humana. Partindo da prerrogativa de que "o sujeito pós-humano é uma amálgama, uma coleção de componentes heterogêneos" (HAYLES, 1999, p. 3, tradução nossa), entendemos que esses componentes não se referem somente à materialidade que constitui a figura pós-humana, mas também à carga múltipla de elementos que compõem sua identidade.

No caso de Frankenstein, os "componentes heterogêneos" que moldam a identidade de seus personagens principais Victor Frankenstein e sua criatura - são diversos: o pensamento iluminista de Locke e Rousseau, os tratados alquímicos de

10 "By definition, a race is an entire population, and ordinarily a very large population: all Mongolians, for example, or all Caucasians. It does not make sense to refer to all monsters (...) as a population category; they are typically loners or monstrous singularities, solitary creatures beyond the bounds of civilization, which is exactly the situation Frankenstein's monster finds himself in after his creator abandons him." Agrippa e Paracelso, os experimentos científicos de Darwin e Galvani, as obras literárias de Wordsworth, Coleridge, Milton e Percy Shelley. No entanto, diante desse amálgama de influências que de certa forma vai ditar muito das ações dos personagens do romance, nenhum vai ser mais fundamental que a própria relação simbiótica que o criador terá com sua criatura, ou seja, a pós-humanidade em Frankenstein é, em grande parte, resultado do compósito de subjetividades de Frankenstein e do monstro.

Assim como outras obras do século XIX, como O médico e o monstro (1886) e O retrato de Dorian Gray (1890), Frankenstein aborda a questão do duplo e seus desdobramentos morais 
e psicológicos. Contudo, diferentemente daqueles livros publicados ao final do Vitorianismo, o romance de Mary Shelley problematiza o sujeito liberal humanista, fundando um conceito de identidade pós-humana. O humanismo considera o indivíduo como proprietário das capacidades que o qualificam como pessoa, não devendo à sociedade nada por isso. Sendo assim, a essência humana é definida pela liberdade da vontade ou do desejo de outros (HAYLES, 1999, p.3). Contudo, essa distinção entre uma agência individual e a vontade dos outros é posta em xeque pelo pós-humano. N. Katherine Hayles, uma das principais teóricas sobre o tema, afirma que

a qualidade coletiva heterogênea do pós-humano implica uma cognição distribuída e localizada em partes distintas (...) que complica a agência individual. Se "a essência humana é a liberdade das vontades dos outros", o pós-humano é "pós" não porque é necessariamente sem liberdade, mas porque não existe maneira a priori de identificar uma vontade própria que pode ser claramente distinta de uma vontade outra. (HAYLES, 1999, p.3-4, tradução nossa).

No caso de Frankenstein, o duplo Victor/monstro apresenta essa qualidade do pós-humano descrita por Hayles. Criador e criatura encontram-se de tal forma unidos, muitas vezes partilhando das mesmas vontades e com características individuais tão semelhantes, que sua relação pode ser lida como a configuração de identidades pós-humanas.

A relação de Frankenstein com o monstro éconstantemente problematizada por Mary Shelley no decorrer da narrativa. A criatura é inicialmente concebida pelo desejo do cientista de controlar forças da natureza e assim alcançar não só a glória, mas também a imensa gratidão desse novo ser, ou seja, uma vontade própria característica da essência humana como descrita por Hayles. Porém, essa liberdade de desejo que possibilitou os experimentos científicos de Frankenstein é colocada em xeque quando a criatura ganha vida. A partir desse momento, o romance embaça os desejos dos dois personagens, sendo em algumas passagens difícil de distinguir qual é a vontade de um e qual a do outro.

Um bom exemplo disso é a subversão do entendimento do duplo mestre/escravo no que se refere a Frankenstein e ao monstro. Se a posição de criador pode dar a Frankenstein inicialmente uma posição de superioridade, à medida que 
a narrativa se desenvolve, as vontades do monstro tomam tamanha proeminência que os desejos de ambos os personagens se fundem, confundindo as posições de uma possível relação hierárquica entre eles. Frankenstein vai dizer que é escravo de sua criatura (SHELLEY, 2017, p.164), e, em outra passagem, quando ele destrói o projeto de companheira do monstro, este afirma "Você é meu criador, mas eu sou seu mestre; obedeça!" (SHELLEY, 2017, p.179).

O desejo de uma companheira também é outro desejo partilhado por Frankenstein e pela criatura. A narrativa é construída de tal maneira que o cientista tem de tomar a decisão de casar-se com Elizabeth, ao mesmo em que tem de escolher se vai sucumbir ao desejo do monstro de ter uma companheira para si - a conexão entre "a vontade própria" e "a vontade outra" do pós-humano se concretiza. O próprio Victor reconhece essa aproximação quando diz:

A ideia de uma união imediata com minha Elizabeth era de horror e tristeza. Estava preso a uma promessa solene, que ainda não havia cumprido e que não ousava quebrar; caso o fizesse, que múltiplas desgraças poderiam recair sobre mim e minha dedicada família! Poderia eu celebrar com esse peso mortal pendurado no pescoço, fazendo-me curvar até o chão? Tinha de cumprir meu compromisso e deixar o monstro partir com sua parceira antes que me permitisse desfrutar o deleite de uma união da qual eu esperava paz. (SHELLEY, 2017, p.163)

Dessa forma, Frankenstein vê que seu desejo (de se casar) só seria realizado quando ele atendesse ao desejo do monstro (de ter uma companheira). É interessante notar que, no original, o uso da palavra engagement para se referir tanto ao compromisso com o monstro quanto a seu relacionamento com Elizabeth, acentua o quanto a liberdade individual de Frankenstein está comprometida.

Ambos os personagens chegam a partilhar das mesmas sensações, sentindo-se infelizes e rejeitados. O monstro diz que é odiado e "a mais infeliz entre as criaturas vivas" (SHELLEY, 2017, p.108), enquanto Frankenstein posteriormente vai dizer que "nenhuma criatura jamais foi tão desolada quanto eu" (SHELLEY, 2017, p.208). Ironicamente, esses sentimentos são causados um pelo outro: Frankenstein se sente miserável devido aos atos odiosos do monstro, e o monstro 
11 Em O paraíso perdido, Satã diz: "Quanto sou infeliz! Por onde posso fugir de sua cólera infinita / E de meu infinito desespero?.../ Só o Inferno essa fuga me depara/ Eu sou Inferno pior!" (Disponível em http:// www.ebooksbrasil. o r g / e L i b r i s / paraisoperdido.html)

12 "Victor and his creature are virtually fused into one being, almost one consciousness, during their final race across the icy wastes of the North Pole. Here, the hunter becomes the hunted, the pursued the pursuer. The creature leaves food for the pursuing Victor so that they can finally reunite. And when each boards Walton's ship, each articulates the same feelings of intermingled revenge, remorse and despair (...) Victor has become his creature, his creature has become his maker; they are each other's double. Hence, naming the creature "Frankenstein" - as popular folklore would have it - uncovers a profound truth within the novel's narrative." se sente miserável em razão das atitudes irresponsáveis de Frankenstein. Até mesmo O paraíso perdido (1667) de John Milton faz parte do repertório de referências dos dois protagonistas: o monstro afirma que "eu, como o diabo primogênito, trazia o inferno dentro de mim" (SHELLEY, 2017, p.145), enquanto Frankenstein vai dizer que "carregava comigo meu inferno perpétuo" (SHELLEY, 2017, p.214) ${ }^{11}$.

Essa comunhão de desejos e sentimentos entre Frankenstein e sua criatura, fundando uma identidade póshumana, acentua-se à medida que a narrativa vai chegando a seu final. É nos confins gelados do Ártico que as subjetividades de ambos se fundem. Como bem resume Anne K. Mellor:

Victor e sua criatura são virtualmente unidos em um único ser, praticamente uma consciência, durante sua perseguição final nas terras geladas do Polo Norte. Aqui, o caçador se torna o caçado, o perseguidor o perseguido. A criatura deixa comida para Victor em sua busca com o objetivo de que eles possam se reencontrar. E quando cada um embarca no navio de Walton, cada um articula os mesmos sentimentos misturados de vingança, remorso e desespero. (...) Victor se tornou sua criatura, e sua criatura se tornou seu criador; eles são o duplo um do outro. Dessa forma, chamar a criatura de "Frankenstein" - como é comum popularmente - revela uma profunda verdade na narrativa do romance (MELLOR, 2003, p. 23, tradução nossa). ${ }^{12}$

Assim sendo, a pós-humanidade em Frankenstein ultrapassa a questão biológica da fusão de diferentes partes de corpos e animais na construção do monstro, para configurar uma identidade pós-humana originada pela fusão de diferentes desejos que problematizam o sujeito liberal humanista.

Se a condição pós-humana do monstro é bastante evidente e a ligação entre ele e seu criador revela novas formas de subjetividade para além do humanismo, o que pode ser dito sobre a identidade singular de Victor Frankenstein? O estudante-cientista de Ingolstadt é visto comumente como ambicioso, egoísta e irresponsável, e, embora haja verdade nessas qualificações, também podemos interpretar que muitas das ações e comportamentos do personagem evidenciam elementos que, de alguma forma, podemos classificar como pós-humanos.

Herdeiro das tradições de Prometeu e Fausto, Frankenstein intenciona ultrapassar os limites impostos pela natureza que 
delimitam sua humanidade. Ao transcender essas convenções, ele incorpora o sentido de "pós" no pós-humano no que se refere à superação de um conceito de "humano", que, a partir de então, passa a ser entendido como ultrapassado. O crítico Andy Mousley resume essa ideia muito bem quando afirma:

O próprio Frankenstein é um ótimo exemplo de um humano cuja humanidade paradoxalmente consiste em um simultâneo reconhecimento e negação dos limites humanos. Como um dos personagens prometeicos mais ousados da literatura, ele exemplifica o pós-humano no humano, ou pelo menos um tipo de pós-humanidade, determinado a se superar. (MOUSLEY, 2016, p.160, tradução nossa.) ${ }^{13}$

De certa forma, a pós-humanidade de Frankenstein tornase mais acentuada quando comparamos suas atitudes com as do monstro. Tropo literário que viria a se tornar recorrente em obras de ficção científica posteriores (especialmente lidando com robôs e androides), Frankenstein apresenta a criatura em diversos momentos com um comportamento muito mais humano que os de seu criador. Um bom exemplo disso é o argumento que o monstro usa para convencer Frankenstein na criação de um segundo ser:

Não destruo a ovelha e o cabrito para saciar meu apetite; bolotas e amoras me dão nutrição suficiente. Minha companheira deve ser da mesma natureza que eu, e ficará satisfeita com o mesmo sustento. Faremos nossa cama de folhas secas; o sol vai brilhar sobre nós e sobre o homem, e vamos colher nosso alimento. $\mathrm{O}$ retrato que apresento a você é pacífico e humano, e você tem de perceber que não pode negar só pela sordidez do poder e da crueldade. (SHELLEY, 2017, p.155)

13 "Frankenstein himself is a prime example of a human whose humanity paradoxically consists in the simultaneous recognition and denial of human limits. As one of literature's most notorious Promethean over-reachers, he exemplifies the posthuman in the human, or at least one kind of posthumanity, bent on surpassing himself."
O monstro, portanto, propõe um tipo de vivência fundada em uma comunhão com outro ser e com a natureza, em que pretende desfrutar das benesses oferecidas por ela sem perturbar a ordem natural das coisas.

Por outro lado, Frankenstein privilegia a solidão, renegando os apelos de seus amigos e familiares. Além disso, viola os limites da natureza torturando animais e subvertendo conceitos biológicos naturais, geralmente agitado e atormentado por uma ambição desmedida. O próprio personagem reconhece a maneira pela qual o estudo do conhecimento científico deve ser conduzido para se preservar a humanidade: 
O ser humano perfeito deve sempre preservar uma mente calma e pacífica e nunca permitir que a paixão ou um desejo transitório perturbe sua tranquilidade. Não acredito que a busca por conhecimento seja uma exceção a essa regra. Se o estudo ao qual você se dedica tende a enfraquecer seus afetos e destruir seu gosto pelos prazeres simples, que nada deveria poluir, então esse estudo certamente não se justifica, não é adequado à mente humana (SHELLEY, 2017, p.63)

Nessa passagem, é como se Frankenstein atestasse sua pós-humanidade. A busca de conhecimento executada pelo personagem no processo de criação do monstro foi caracterizada exatamente pela perturbação da tranquilidade, enfraquecimento de afetos, e destruição do gosto por prazeres simples. Assim sendo, ao criar um novo ser, "ele reprime aquela parte da humanidade que persiste em lhe dizer que algo com relação a sua ambição é moralmente repugnante" (MOUSLEY, 2016, p.164, tradução nossa).

A criação do monstro, dessa forma, pode ser interpretada como a gênese não apenas de um conceito de pós-humanidade no que se refere a uma suposta nova espécie (na figura da criatura), mas também no que se refere a uma ideia de humano pós-humano, em que os limites da humanidade do criador são problematizados. Ao criar o monstro, Frankenstein descontrói sua humanidade e constrói uma identidade pós-humana. Judith Halberstam chega a dizer que "embora superficialmente o romance pareça ser sobre a criação de um monstro, é na verdade sobre a criação de um humano" (HALBERSTAM, 1995, p. 38). De acordo com o que foi apresentado nesse trabalho, podemos dizer, no entanto, que Frankenstein vai além: é um romance sobre a criação do pós-humano.

Duzentos anos após sua publicação, Frankenstein ainda assombra os meios literários e científicos. Influenciado por teorias e experimentos do início do século XIX, o romance ajudou a fundar conceitos que se tornariam fundamentais para discutir a ficção científica e a tecnociência nos séculos XX e XXI, em especial no que se refere ao pós-humano e a seus desdobramentos. A história de Mary Shelley, com sua revolucionária visão sobre os limites entre a natureza e a ciência, permanece como fundamental referência para o entendimento da (pós)humanidade. 


\section{REFERÊNCIAS}

BRANTINGLER, Patrick. Race and Frankenstein. In: SMITH, Andrew (ed.) The Cambridge Companion to Frankenstein. Cambridge: Cambridge University Press, 2016, p.127-142.

BROGLIO, Ron. Romantic. In: LARKE, Bruce \& ROSSINI, Manuela (eds.) The Cambridge Companion to Literature and the Posthuman. Cambridge: Cambridge University Press, 2017, p.29-40.

CLARKE, Bruce \& ROSSINI, Manuela (eds.) The Cambridge Companion to Literature and the Posthuman. Cambridge: Cambridge University Press, 2017.

CLEMIT, Pamela. Frankenstein, Matilda, and the legacies of Godwin and Wollstonecraft. In: SCHOR, Esther (ed.) The Cambridge Companion to Mary Shelley. Cambridge: Cambridge University Press, 2003, p.26-44.

FOUCAULT, Michel. As Palavras e as Coisas. São Paulo: Martins Fontes, 1999.

GILBERT, Sandra M. \& GUBAR, Susan. Mary Shelley's monstrous Eve. In: SHELLEY, Mary. Frankenstein: a Norton critical edition. New York: W.W. Norton \& Company, 1996, p.225-240.

HALBERSTAM, Judith. Skin Shows: Gothic Horror and the Technology of Monsters. Durham: Duke University Press, 1995.

HASSAN, Ihab. Prometheus as Performer: Toward a Posthumanist Culture?. The Georgia Review 31, p.i830-850. 1977.

HAYLES, N. Katherine. How We Became Posthuman: Virtual Bodies in Cybernetics, Literature, and Informatics. Chicago: The University of Chicago Press, 1999.

HITCHCOCK, Susan Tyler. Frankenstein: as muitas faces de um monstro. São Paulo: Larousse do Brasil, 2010. 
HOLMES, Richard. The Age of Wonder: The Romantic Generation and the Discovery of the Beauty and Terror of Science. Londres: Vintage Books, 2010.

HOUE, Ulf. Frankenstein without electricity: contextualizing Shelley's novel. Studies in romanticism, Vol. 55. Boston: Boston University, p.95-118. 2016.

MELLOR, Anne K. Making a 'monster': an introduction to Frankenstein. In: SCHOR, Esther (ed.) The Cambridge Companion to Mary Shelley. Cambridge: Cambridge University Press, 2003, p.9-25.

MOUSLEY, Andy. The posthuman. In: SMITH, Andrew (ed.) The Cambridge Companion to Frankenstein. Cambridge: Cambridge University Press, 2016, p.158-171.

SCHOR, Esther (ed.) The Cambridge Companion to Mary Shelley. Cambridge: Cambridge University Press, 2003.

SHELLEY, Mary. Frankenstein. Rio de Janeiro: Zahar, 2017.

SMITH, Andrew (ed.) The Cambridge Companion to Frankenstein. Cambridge: Cambridge University Press, 2016.

VARGO, Lisa. Contextualizing sources. In: SMITH, Andrew (ed.) The Cambridge Companion to Frankenstein. Cambridge: Cambridge University Press, 2016. p.26-39.

WOLFE, Cary. What is Posthumanism? Minneapolis: University of Minnesota Press, 2010.

WOLFSON, Susan \& LEVAO, Ronald (eds.). The annotated Frankenstein. Cambridge: Belknap Harvard, 2012. 


\section{Abstract \\ The monstrous science in Frankenstein: aspects of the posthuman}

The objective of this work is to investigate the ways in which the discoveries and the scientific thought in the end of the $18^{\text {th }}$ century and beginning of the $19^{\text {th }}$ century (the period known as the Second Scientific Revolution) influenced the writing of Mary Shelley's novel Frankenstein (1818), as well as to analyze how this work presents aspects which contribute to the study of the posthuman. Frankenstein was written during a period of profound revolutions in philosophical and scientific thought that informed several elements present in the novel: the social theories of William Godwin and Mary Wollstonecraft, Erasmus Darwin's hypotheses about the origin of life, Luigi Galvani's experiments with electricity, among others. On the other hand, in a contemporary perspective, Frankenstein is a work that inaugurates many aspects that would be read through the prism of the posthuman. When describing the possible (and terrible) consequences of the connection between the human sphere and those of the animal and of the technological, the novel problematizes the privileged position of man in nature. Considering the physical and biological features of the monster, Frankenstein's wish in overcoming the limits of nature, and the complex relation between both characters regarding the binomial desire/freedom, the novel can be read as one of the greatest representatives of the concept of posthumanity in literature.

Keywords: Frankenstein, science, posthuman. 